\title{
O Direito da pessoa idosa à educação formal no Brasil: um caminho para o exercício da cidadania
}

\author{
The right of the elderly to formal education in Brazil: a way to exercise citizenship
}

Patrícia Mattos Amato Rodrigues ${ }^{1}$ Simone Caldas Tavares Mafra ${ }^{2}$ Eveline Torres Pereira ${ }^{3}$

\section{Resumo}

O envelhecimento da população é uma realidade brasileira e mundial. Atualmente os idosos brasileiros representam um contingente de 26 milhões de pessoas, podendo chegar a 37,9 milhões em 2027. Aos idosos brasileiros foram assegurados, pela Constituição Federal de 1988 e de leis especiais, os direitos necessários a uma vida digna e a uma participação social cidadã. Neste contexto, o direito à educação apresenta-se como importante instrumento na construção da cidadania e na promoção da dignidade da pessoa humana, razão pela qual este estudo busca investigar a importância do acesso à educação formal para a promoção da cidadania do idoso brasileiro. Trata-se de pesquisa de abordagem qualitativa, descritiva e exploratória, com coleta documental e bibliográfica dos dados. Os resultados apontam um sujeito negligenciado, que não se faz presente na pauta das políticas educacionais, sendo necessário se pensar o idoso como detentor do direito à educação e formular políticas públicas de acesso e permanência para assegurar o exercício a este direito.

Palavras-chave: Envelhecimento; Educação; Direito à Educação; Cidadania.

\begin{abstract}
The aging of the population is a Brazilian and worldwide reality. Currently the Brazilian elderly represent a contingent of 26 million people, reaching 37.9 million in 2027. The Brazilian elderly were assured, through the Federal Constitution of 1988 and of special laws, the necessary rights to a dignified life and to a citizen's social participation. In this context, we discuss the right to health, the right to leisure, to accessibility, but little is said about the right to education, although this is a fundamental right of recognized relevance; which is why this study seeks to investigate the importance of access to formal education for the promotion of citizenship of the Brazilian elderly. This is a qualitative, descriptive and exploratory research, with documentary and bibliographic data collection. The results point to a neglected subject, which is not present in the educational policy agenda, and it is necessary to think of the elderly as having the right to education and to formulate public policies of access and permanence to ensure the exercise of this right.
\end{abstract}

Keywords: Aging; Education; Right to education; Citizenship.

\footnotetext{
1 Doutoranda e Mestre em Economia Doméstica pela Universidade Federal de Viçosa (UFV). Graduada em Direito pela Universidade Federal de Juiz de Fora (UFJF). Professora e Coordenadora do curso de Direito na Faculdade Presidente Antônio Carlos de Ubá (FUPAC Ubá). E-mail: patyamato@yahoo.com.br

2 Doutora em Engenharia de Produção pela Universidade Federal de Santa Catarina (UFSC). Professora Associada do Programa de Pós-Graduação em Economia Doméstica da Universidade Federal de Viçosa (UFV). E-mail: sctmafra@ufv.br

${ }^{3}$ Doutora em Educação Física e Cultura pela Universidade Gama Filho. Professora Associada da Universidade Federal de Viçosa (UFV), e coordenadora do Programa de Atividade Física Adaptada (PROAFA), que engloba projetos interdisciplinares de extensão voltados para pessoas com deficiência e/ou transtorno mental. E-mail: etorres@ufv.br
} 


\section{INTRODUÇÃO}

Dados estatísticos, ampla e sistematicamente divulgados, apontam para o envelhecimento da população mundial ${ }^{4}$. Trata-se de fenômeno novo, de repercussões múltiplas e intensas, representando desafio tanto para sociedades desenvolvidas como para sociedades em desenvolvimento, a exemplo do Brasil.

De fato, em pouco mais de três décadas o número de idosos brasileiros será triplicado 5 , deixando de ser conhecido como o "país do futuro" para se tornar um "jovem país de cabelos brancos", na feliz expressão de Veras ${ }^{6}$. Projeções do Instituto Brasileiro de Geografia e Estatística (IBGE) apontam que em 2025 o Brasil terá aproximadamente 32 milhões de pessoas na terceira idade - isto é, acima dos 60 anos, o que representará 15\% da população, colocandoo em 6ํlugar no ranking mundial em número de idosos.

Os números do envelhecimento populacional refletem transformações sociais igualmente expressivas e rápidas, dentre as quais as mudanças na nupcialidade com a postergação dos matrimônios, a queda da fecundidade e o ingresso maciço das mulheres no mercado de trabalho merecem o destaque de Camarano (2010).

Mas, a importância de se estudar o envelhecimento no Brasil não se limita ao impacto dos números. Como bem adverte Ramos (2014, p.21), "os velhos não são apenas uma questão numérica, mas especialmente uma questão social, motivo pelo qual o envelhecimento populacional precisa ser analisado com muita cautela".

A preocupação em melhor entender o processo de envelhecimento, bem como de otimizar a qualidade de vida dos idosos é cada dia mais frequente e investigada em caráter multidisciplinar (SILVA, 2011), sendo também objeto de produção legislativa especializada.

No Brasil, além das garantias constitucionais ${ }^{7}$ os direitos dos idosos encontram-se assegurados por leis especiais, notadamente pela Lei 8.842/1994 (dispõe sobre a Política Nacional do Idoso) e Lei 10.741/2003 (Estatuto do Idoso). Tais diplomas normativos reconhecem

\footnotetext{
${ }^{4}$ Segundo dados da OMS - Organização Mundial da Saúde, o envelhecimento populacional atinge países desenvolvidos e em desenvolvimento, sendo, por esta razão, classificado como fenômeno mundial. Dados e projeções apontam que em 2025 serão 1,2 bilhão de idosos, representando aumento de $223 \%$ em pouco mais de 50 anos. Fonte: http://www.paho.org/bra. Acesso em: 28 de set. 2017.

${ }^{5}$ Nos últimos 60 anos, o número absoluto de pessoas com mais de 60 anos aumentou nove vezes. Em 1940 era de 1,7 milhão e em 2000, de 14,5 milhões. Projeta-se para 2020 que um contingente de aproximadamente 30,9 milhões de brasileiros terão mais de 60 anos segundo Beltrão, Camarano e Kanso (2004).

${ }^{6}$ Renato Peixoto Veras, médico e diretor da Universidade Aberta da Terceira Idade, autor do livro "País jovem com cabelos brancos".
}

${ }^{7}$ Artigos 1ำ 14, 40, 201, 203, 229 e 230 da Constituição Federal Brasileira de 1988. 
a necessidade de oportunizar às pessoas idosas todas as formas de interação social e de desenvolvimento pessoal oferecidas aos integrantes de outras faixas etárias.

Neste contexto, merece especial destaque o direito à educação, sendo necessário é percebê-lo como fonte de promoção da cidadania, por meio da gama de relacionamentos e da construção de saberes reflexivos que suscita. O direito à educação cumpre assim relevante propósito social na medida em que promove a dignidade da pessoa humana.

Segundo Vogt e Alves (2005, p.196), “A educação tem sido parte integrante da cultura em qualquer época da história". Sobretudo após a industrialização, há consenso mundial acerca da necessidade de se oportunizar a todos o acesso à educação escolar, sendo serviço cada vez mais consumido e tendo papel decisivo no desenvolvimento econômico e social de uma nação.

Afirma-se, com base na Carta Magna de 1988, que o direito à educação é direito fundamental, isto significa dizer que se trata de direito a serviço da dignidade da pessoa humana. A educação é direito de todos e pode contribuir na manutenção e reinserção do idoso na sociedade, razão pela qual este estudo qualitativo, descritivo e exploratório, tem como objetivo investigar a importância do acesso à educação formal para a promoção da cidadania do idoso brasileiro, por meio da pesquisa bibliográfica e documental.

Segundo Bezerra, Almeida e Therrien (2012) os estudos acerca do envelhecimento populacional e das suas consequências nas nações em desenvolvimento é centrado em abordagens relacionadas às condições de saúde, aposentadoria e arranjos familiares. Seale e Kops (2012) enfatizam a escassez de pesquisas sobre idosos que participam de atividades educacionais, não obstante serem estas atividades oferecidas e desenvolvidas em ambiente acadêmico, vocacionado à pesquisa.

Tal panorama indica que as grandes temáticas 'educação' e 'envelhecimento' ainda carecem de exploração conjunta, o que aponta para a utilidade e originalidade da pesquisa.

Como identificar a pessoa idosa diante das múltiplas velhices? Qual nomenclatura utilizar para tratar tecnicamente o sujeito que envelhece e o processo por ele vivenciado? Quais são seus direitos? A educação é um deles? O direito à educação dos idosos está contemplado de forma suficiente e coesa na legislação nacional especializada? O que dizem os indicadores estatísticos? Envelhecimento e educação são realidades que se somam em prol da cidadania da pessoa idosa ou se repelem demonstrando a negligência das políticas públicas educacionais. Estas questões orientaram o estudo e para respondê-las fez-se necessário identificar a pessoa idosa, contextualizando-a. 


\section{IDENTIFICANDO A PESSOA IDOSA: UMA CARACTERIZAÇÃO LEGAL E SOCIAL}

Estabelecer e identificar, na sociedade atual, quem é "idoso" consiste em tarefa complexa e com alto grau de falibilidade, isto porque o conceito de pessoa idosa varia a depender dos critérios adotados e da sociedade em que este sujeito se encontra inserido.

Martinez (2012) aponta cinco critérios para identificação da pessoa idosa, o cronológico, o psicobiológico, o econômico-financeiro, o social e o legal. Explica o jurista que, para o critério cronológico, pessoa idosa é quem contabiliza e comprova, pela via documental, vários anos de vida, enquanto para o critério psicobiológico são ressaltadas as condições mentais e biológicas dos indivíduos, independentemente do número de anos aferidos documentalmente. O primeiro critério é objetivo e, por esta razão, fácil de ser utilizado, o segundo é marcado pela subjetividade, estando a sofrer significativas variações a depender de cada indivíduo, da sua ancestralidade e de sua história de vida. O terceiro critério, parte do falso pressuposto de que toda pessoa idosa é hipossuficiente em termos econômicos, estando, por esta razão, a necessitar de amparo e proteção financeira dos mais jovens, da família e do Estado. O critério social caracteriza a pessoa idosa de acordo com o ambiente e as relações sociais que vivencia e, por derradeiro, o critério legal entende por pessoa idosa aquele assim estabelecido na lei vigente em determinado local e tempo.

Ramos (2014) apresenta classificação mais concisa em que identifica como critérios de caracterização da pessoa idosa o cronológico, o fisiológico e o subjetivo. O primeiro alcançado quando se atinge certa idade (no Brasil, 60 anos), o segundo diante do declínio funcional do organismo e o terceiro quando há autopercepção da velhice.

Pela proximidade dos argumentos, invoca-se Bobbio ${ }^{8}(1997)$ que propõe três parâmetros para fins de identificação do idoso, a saber: o cronológico ou censitário, o burocrático e o psicológico ou subjetivo. O primeiro e o segundo são formais e generalistas, posto não se atentarem para as particularidades do indivíduo, mas apenas e respectivamente para a quantidade de anos por ele vividos e para o acesso a benefícios disponibilizados pelo Estado e pela iniciativa privada, tais como aposentadoria, passe livre nos transportes coletivos, prioridade nas filas e meia-entrada em eventos culturais. O terceiro parâmetro é de ordem subjetiva, pressupondo o auto reconhecimento do sujeito como idoso, sendo assim vivenciado pelo jurista.

\footnotetext{
${ }^{8}$ Filósofo e historiador político, cuja obra tem grande relevância para as ciências socais, sobretudo, pela lógica, densidade e concisão.
} 
A objetividade do parâmetro cronológico ou censitário, ainda que criticável por não se atentar para o curso de vida dos sujeitos desenvolvidos, é a mais utilizada pelas legislações, por oferecer segurança jurídica, dando a garantia necessária ao desenvolvimento das relações sociais.

Dando destaque para as limitações do critério cronológico/legal Mascaro (1997, p.30) reconhece que "o principal critério estipulado para situar as categorias etárias é a data de aniversário das pessoas, embora seja um indicativo grosseiro do envelhecimento, visto que é um processo biológico, psicológico, sociológico e cultural."

Neste sentido Diniz (2011, p.6) afirma "no caso do Brasil, o estabelecimento da velhice se dá através do critério cronológico, adotado pela lei".

A opção legal brasileira pelo critério cronológico remonta ao período do Império. De fato, merece registro que em 28 de setembro de 1885 foi promulgada a Lei 3.270, conhecida como Lei dos Sexagenários. Tratava-se de lei abolicionista ${ }^{9}$ que determinava que os escravos ao completarem sessenta anos seriam libertos sob a condição de trabalharem por mais três anos para indenizarem os ex-senhores pela alforria que Ihes seria concedida.

Art. $3^{\circ} \S 10$. São libertos os escravos de 60 anos de idade, completos antes e depois da data em que entrar em execução esta Lei; ficando, porém, obrigados, a título de indemnização pela sua alforria, a prestar serviços a seus ex-senhores pelo espaço de três anos. (BRASIL, 1885)

Diante das péssimas condições em que viviam, poucos eram os escravos que conseguiam chegar aos sessenta anos e os que chegavam e eram "beneficiados" pela alforria se deparavam com a penúria, na medida em que libertos não tinham condições mínimas de sobrevivência (alimento e teto), deixando a condição de escravos para se transformarem em mendigos, vez que o amparo previsto no $\S 13$ do Art. $3^{\circ}$ da referida lei era negligenciado pelos senhores donos de escravos.

Art. $3^{\circ} \S 13$. Todos os libertos maiores de 60 anos, preenchido o tempo de serviço de que trata o $\S 10$, continuarão em companhia de seus ex-senhores, que serão obrigados a alimentá-los, vesti-los, e trata-los em suas moléstias, usufruindo os serviços compatíveis com as forças deles, salvo si preferirem obter em outra parte os meios de subsistência, e os Juízes de Orphãos os julgarem capazes de o fazer. (BRASIL, 1885)

A Lei 10.741/2003 - Estatuto do Idoso, em seu primeiro artigo estabelece o marco etário de sessenta anos para a identificação do sujeito idoso no Brasil seguindo o mesmo parâmetro

${ }_{9}^{9}$ Para muitos a referida lei não tinha ideais abolicionistas, ao contrário visava aplacá-los, na medida em que criava uma falsa percepção de evolução no tratamento da questão escravocrata brasileira. 
da Lei 8.842/1994 que estabelece a Política Nacional do Idoso e cria o Conselho Nacional do Idoso.

O critério adotado pela legislação brasileira especializada mostra-se coerente com o disposto pela Organização Mundial da Saúde - OMS ${ }^{10}$, que em 1963, empreendeu divisão das faixas etárias considerando como de "meia idade" os indivíduos de 45 a 59 anos, "idosos" aqueles compreendidos na faixa etária dos 60 aos 74 anos, "anciãos" os de 75 a 90 anos e "velhice extrema" acima dos 90 anos.

Vieira e Nascentes (2004) fazem registro de que no Brasil em 1930 eram consideradas idosas as pessoas com mais de cinquenta anos e em 1945 o marco etário já teria alcançado os indivíduos a partir dos sessenta anos. A própria OMS que, em países em desenvolvimento, identifica o idoso a partir dos sessenta anos, nos países desenvolvidos sobe o marco etário para sessenta e cinco, evidenciando a necessidade de contextualizar o indivíduo.

Mesmo o Estatuto do Idoso, ainda que fiel ao critério cronológico, estabeleceu duas categorias de beneficiários: a dos maiores de sessenta e cinco anos, que gozam de todos os direitos do estatuto, inclusive do benefício assistencial do LOAS $^{11}$ e da gratuidade dos transportes coletivos ${ }^{12}$ e outra, na faixa etária compreendida entre os sessenta e os sessenta e cinco anos, beneficiária dos direitos remanescentes: alimentos ${ }^{13}$, atendimento de saúde prioritário ${ }^{14}$, acompanhante em caso de internação ${ }^{15}$, vagas prioritárias para estacionamento de veículos ${ }^{16}$, além de prioridade na tramitação de processos judiciais e administrativos ${ }^{17}$.

Dada a variedade de critérios para fins de identificação da pessoa idosa, bem como a mutabilidade dos mesmos em razão do tempo e do lugar e considerando ainda que as condições

10 Dados disponíveis em:<http//gerontounivali.wordpress.com/conceito-de-idoso//>. Acesso em 02 mai. 2018.

${ }^{11}$ Art. 34. Aos idosos, a partir de 65 (sessenta e cinco) anos, que não possuam meios para prover sua subsistência, nem de tê-la provida por sua família, é assegurado o benefício mensal de 1 (um) salário-mínimo, nos termos da Lei Orgânica da Assistência Social - Loas.

${ }^{12}$ Art. 39. Aos maiores de 65 (sessenta e cinco) anos fica assegurada a gratuidade dos transportes coletivos públicos urbanos e semi-urbanos, exceto nos serviços seletivos e especiais, quando prestados paralelamente aos serviços regulares.

13 Art. 11. Os alimentos serão prestados ao idoso na forma da lei civil.

${ }^{14}$ Art. $15 . \S 4 \circ$ Os idosos portadores de deficiência ou com limitação incapacitante terão atendimento especializado, nos termos da lei.

${ }^{15}$ Art. 16. Ao idoso internado ou em observação é assegurado o direito a acompanhante, devendo o órgão de saúde proporcionar as condições adequadas para a sua permanência em tempo integral, segundo o critério médico.

${ }^{16}$ Art. 41. É assegurada a reserva, para os idosos, nos termos da lei local, de $5 \%$ (cinco por cento) das vagas nos estacionamentos públicos e privados, as quais deverão ser posicionadas de forma a garantir a melhor comodidade ao idoso.

17 Art. 71. É assegurada prioridade na tramitação dos processos e procedimentos e na execução dos atos e diligências judiciais em que figure como parte ou interveniente pessoa com idade igual ou superior a 60 (sessenta) anos, em qualquer instância. 
de vida da população exercem influência direta no critério adotado, tem-se justificada a impossibilidade de oferecer uma regra geral que contemple, de forma satisfatória, todos os indivíduos.

\section{ENVELHECER: UMA QUESTÃO SOCIAL RELEVANTE}

Ramos (2014), trabalhando a gênese da ideia de velhice, afirma que o ciclo de vida humano compreende o nascimento, o crescimento ou desenvolvimento, a maturidade e a morte. Entretanto, segundo o mesmo autor (2014, p.12), essas etapas da vida "não eram, até antes da consolidação do modelo de sociedade capitalista, objeto de saberes". Sobre a velhice não incidia nenhum valor, nenhum discurso, nenhum saber, nenhuma preocupação. Não era tema de relevância.

A finitude é um dado da natureza humana, no dito popular, trata-se da única certeza da vida. Contudo, a duração da vida não era preocupação das sociedades pré-industriais ${ }^{18}$, pois o número maior ou menor de anos vividos em nada mudava o desenvolvimento e as possibilidades de acesso dos indivíduos. De fato, vivendo numa sociedade sem mobilidade social, ser nobre ou ser servo era condição dada pelo nascimento, inquestionável e imutável.

O que se quer evidenciar é a ausência de motivação social para viver mais, pois a quantidade de tempo vivido não teria nenhuma interferência na qualidade de vida.

Outros importantes fatores a serem considerados são as péssimas condições sanitárias e as limitações médicas e farmacológicas, que, conjuntamente, contribuíam para que poucos indivíduos chegassem à condição de idosos.

Sendo vivenciada por poucos, a velhice era tratada como condição biológica do indivíduo. Era benesse ou calvário privado, que deveria ser administrado por cada família que o vivenciava. Não havia, portanto, mobilização social em torno do processo de envelhecimento.

Junto com o processo de industrialização surge a figura do burguês e, com a prática comercial, a possibilidade de ascender socialmente. Para esta nova classe social, a duração da vida passou a ser uma preocupação, pois quanto mais se vivia, mais tempo se tinha para avançar econômica e socialmente.

Viver mais tempo passa a ser objeto de desejo e para alcançá-lo são feitos investimentos na melhoria das condições sanitárias das cidades e no desenvolvimento de fármacos e tecnologia médica. O resultado é significativo e crescente aumento da expectativa de vida,

18 Denominação que faz referência a forma de organização econômica das sociedades anteriores à Revolução Industrial. 
fazendo com que o envelhecer deixe a condição de fenômeno exclusivamente biológico e passe a condição de fenômeno socialmente relevante.

Também merece registro o fato de que a industrialização trouxe consigo a crescente especialização do processo produtivo, tornando necessário investir na capacitação da mão-deobra. Quanto mais tempo durassem as aptidões dos indivíduos para o trabalho, melhores seriam os resultados dos investimentos o que justifica a preferência pela mão de obra mais jovem em detrimento da mão-de-obra dos mais velhos. Assim, o processo de industrialização contribuiu para a valorização do novo e para a depreciação do velho, associando os atributos de capacidade e disposição para o trabalho aos jovens e a incapacidade e letargia aos velhos.

O desenvolvimento da medicina ganha especial importância, na medida em que favorece e propicia aumento da capacidade produtiva e da "vida útil" do trabalhador, tornando o discurso médico de grande interesse econômico e, desde então, assegurando status a estes profissionais.

A ideia de faixas etárias, de fases de vida, é apontada como necessidade de sistematização do discurso médico. Para Ramos (2014, p.24) "as etapas etárias do homem foram atribuídos valores diferenciados, de acordo com sua utilidade para a produção e reprodução da riqueza".

A existência de crescente número de velhos nas famílias e a incapacidade econômica, de grande parte delas, para gerir a situação de dependência e as necessidades dos mesmos, transformou o envelhecimento em relevante questão social.

As famílias e os próprios idosos passaram a demandar do Estado políticas públicas específicas, destinadas a assegurar dignidade aos cidadãos que envelhecem.

A resposta institucionalizada do Estado vem sendo construída em ritmo lento e inconstante, e as nações desenvolvidas por terem envelhecido depois de crescerem e de forma mais gradativa, têm conseguido oferecer melhores respostas às lutas políticas destinadas à garantia da dignidade do idoso.

De fato, apesar de universal, a transição demográfica apresenta feições muito variadas, sobretudo quando se comparam países em desenvolvimento com países desenvolvidos, pois nestes os ganhos associados à longevidade decorrem, historicamente, de melhor qualidade de vida, sendo processo gradual e acompanhado por crescimento socioeconômico. Já nos países em desenvolvimento, as conquistas médicas e tecnológicas foram importadas e implantadas, sendo, por esta razão, artificiais, na medida em que não representam avanço autêntico das políticas públicas nacionalmente implementadas (KALACHE, 1987).

Brito (2008, p.12) em importante artigo acerca das peculiaridades da transição demográfica brasileira, lembra que: "os países desenvolvidos, quando estavam na fase atual da 
transição demográfica brasileira, tinham não apenas uma economia com crescimento sustentado, mas também um Estado do Bem-Estar Social consolidado".

Neste sentido, para países em desenvolvimento como o Brasil, o desafio de se preparar socialmente para o envelhecimento populacional é ainda maior, pois, vive-se a-transição muito rápida do bônus para o ônus demográfico.

Necessário se faz esclarecer que o bônus ou janela de oportunidade demográfica ocorre enquanto o crescimento da população economicamente ativa (PEA) é superior ao da população total, havendo contribuição da demografia para a economia, na medida em que se verifica declínio no percentual de cidadãos dependentes - crianças e idosos. Neste contexto, é importante pensar e implementar políticas públicas destinadas a fazer com que os países se aproveitem desta janela de oportunidade demográfica, de maneira a crescer e enriquecer, criando estrutura adequada para vivenciar o ônus demográfico do envelhecimento (OMS, 2005).

Segundo dados divulgados pelo IPEA - Instituto de Pesquisa Econômica Aplicada ${ }^{19}$, o Brasil vive o bônus demográfico até 2030, devendo se preparar para um declínio na relação PEA/População total, pois em razão do aumento na expectativa de vida e da queda na taxa de fecundidade, o número de brasileiros dependentes (no caso, os idosos podem ser considerados parte desse extrato) irá aumentar exponencialmente a partir de então, implicando na necessidade de se repensar a sociedade e capacitá-la para atender aos novos desafios impostos pelo envelhecimento populacional.

Sem dúvida, uma grande questão social que já se põe e que foi exaustivamente discutida no último ano diz respeito à necessidade de se empreender uma reforma previdenciária no Brasil. A justificativa é o envelhecimento populacional, vez que o número de idosos com direito à aposentadoria e a duração do benefício tem aumentado muito mais que o número de jovens que são absorvidos pelo mercado de trabalho, dando suporte econômico ao pagamento dos benefícios.

Contudo, é necessário dizer que os idosos brasileiros não têm a mesma origem e histórico de vida, são pessoas díspares, oriundas de regiões e classes sociais muito distintas. A imensa desigualdade social, vivida também em outras fases: infância, adolescência, juventude e vida adulta, impõe velhices diferentes aos brasileiros.

Inserida e articulada em contexto de desequilíbrio e desigualdades, a transição demográfica no Brasil é original, na medida em que substancialmente distinta da transição demográfica de outras nações, ainda que hajam similitudes, mas não é neutra. Ela é um processo

${ }^{19}$ Disponível em: http://www.ipea.gov.br/agencia/images/stories/capt12 estrutura.pdf. Acesso em: 20 de set. 2016. 
que tanto pode potencializar o crescimento e o bem-estar social, quanto as adversidades econômicas e sociais, ampliando desigualdades já existentes no país.

Há que se buscar o caminho do crescimento e do bem-estar, estando este, para todas as faixas geracionais, associado ao acesso à educação - direito fundamental constitucionalmente assegurado aos brasileiros.

\section{A EDUCAÇÃO COMO DIREITO FUNDAMENTAL}

A Constituição Federal em vigor foi promulgada em 05 de outubro de 1988 e, desde então, é a norma fundamental do Estado Brasileiro, tendo como função unificar e validar as normas jurídicas existentes e regradoras da comunidade política nacional, as quais a partir e em razão dela, estruturam e organizam o sistema jurídico pátrio, conferindo direitos e garantias aos cidadãos.

Trata-se de uma Constituição escrita que contempla normas material e formalmente constitucionais, posto que além de tratar de assuntos especificamente constitucionais, tais como: direitos fundamentais, atribuições, estrutura e organização do Estado, também contempla assuntos outros, tais como as relações familiares, política urbana, agrícola e fundiária.

Enumerada como um dos direitos sociais, a temática da educação formal ${ }^{20}$ foi desenvolvida mais à frente, nos artigos 205 a 214 do texto constitucional, juntamente com a cultura e o desporto. Ainda que não tenha sido pioneira no tratamento da temática ${ }^{21}$, a Carta Constitucional de 1988 contempla a educação como "direito fundamental da pessoa humana, tutelado e garantido pela força da organização e controle social" (LIBERATTI, 2004, p.210).

O mérito do legislador constituinte de 1988 foi ampliar o compromisso do Estado com o ensino público e com o seu financiamento, além de perceber que para assegurar a efetividade do direito à educação era necessário dotá-lo de princípios integradores, que os ligassem aos demais direitos e garantias individuais.

Afirma-se, com base na Carta Magna de 1988, que o direito a educação é direito fundamental, isto significa dizer que se trata de um direito a serviço da dignidade da pessoa

\footnotetext{
20 De acordo com o MEC, a educação formal é oferecida pela rede de ensino pública e privada tradicionais; a não formal corresponde às iniciativas autônomas de aprendizagem que acontecem fora dos sistemas de ensino.

${ }^{21}$ Liberati (2004) informa que a Constituição de 1824 - a primeira Constituição Brasileira, consagrou como direito individual a gratuidade do ensino público primário, sendo a pioneira ao dispor sobre a temática educacional. Ainda que de forma sucinta, todos os diplomas constitucionais brasileiros se dedicaram ao tema, evidenciando uma responsabilidade compartilhada da família e do Estado no que se refere ao acesso, condução e custeio, sendo que a Constituição de 1937 previa uma "contribuição módica e mensal para a caixa escolar".
} 
humana, neste sentido Sarmento (2016, p.135) adverte que devem ser considerados fundamentais os direitos que, contidos expressamente ou não no texto constitucional22, "representem concretizações relevantes do princípio da dignidade da pessoa humana".

Segundo Nunes (2002), a dignidade da pessoa humana é construção histórica, pautada pela prática social e pela razão jurídica que, no texto constitucional de 1988, assume a condição de fundamento do Estado brasileiro. Sarlet (2003, p.120) complementa e esclarece: "a dignidade da pessoa humana atua simultaneamente como limite dos direitos e limite dos limites, isto é, barreira última contra a atividade restritiva dos direitos fundamentais".

Por se tratar de construção histórica, o conteúdo e o alcance do princípio da dignidade da pessoa humana, bem como dos direitos fundamentais que têm por função concretizá-lo, estão em constante processo de modificação e adaptação às novas necessidades, experiências e demandas sociais.

Por não serem os mesmos em todas as épocas e sociedades, necessária se faz investigação histórica no sentido de melhor entender o processo de "maturação" dos direitos fundamentais.

Assim, somente a partir do momento em que o Estado passou a ser compreendido como uma instituição a serviço dos cidadãos, não sendo mais uma construção divina com o fim em si mesmo é que os direitos fundamentais passaram à condição de protagonistas do ordenamento jurídico.

Para fins didáticos a evolução dos direitos fundamentais é dividida em gerações ou dimensões ${ }^{23}$. Esta divisão é importante, pois permite visualizar a construção do conteúdo e o alcance dos mesmos a partir de demandas ditadas por necessidades históricas. Assim, tem-se como direitos fundamentais de primeira dimensão aqueles que visam promover a dignidade humana pela garantia às liberdades individuais, tais como: liberdade de locomoção, culto, reunião, consciência; assegurando o direito de ir e vir, de posicionar-se politicamente e constituir patrimônio.

\footnotetext{
22 Martins (2017, p. 729-730) esclarece: "não há como sustentar a tese de que os direitos fundamentais são apenas aqueles positivados na Constituição. Eles o são, é claro, mas não são os únicos. A própria Constituição reconhece a existência de outros direitos fundamentais não previstos expressamente", existindo direitos fundamentais implícitos, decorrentes de princípios constitucionais, bem como direitos fundamentais fruto da pactuação de Tratados Internacionais.

${ }^{23}$ Classificação criada por Karel Vasak e difundida por Norberto Bobbio na obra "A Era dos Direitos". Vasak divide os direitos fundamentais em três gerações, de acordo com o contexto histórico que justificaram a positivação destes direitos. O termo "gerações" é criticado pela ideia de finitude que apresenta, gerando a falsa percepção de que os direitos de uma geração seriam suplantados por outra, o que não é verdade, já que os direitos de cada geração se agregam ao ordenamento jurídico, havendo relação de coexistência e complementariedade, razão pela qual o termo "geração" vem sendo substituído por "dimensão".
} 
Os direitos fundamentais de primeira dimensão tinham como paradigma a autonomia pessoal, sendo, portanto, direitos "negativos" em relação ao Estado. Foram construídos e positivados à luz da concepção liberal de Estado e, por esta razão, buscavam abstenção dos governantes, criando obrigações de não fazer, impedindo ou limitando a intervenção estatal na vida de cada indivíduo.

Mendes, Coelho e Branco (2007, p. 223) afirmam: "A preocupação em manter a propriedade servia de parâmetro e limite para a identificação dos direitos fundamentais, notandose pouca tolerância para as pretensões que Ihes fossem colidentes".

De fato, tais direitos foram concebidos à época das Revoluções Americana (1776) e Francesa (1789) em que a classe de comerciantes em ascensão, denominada burguesia, buscava liberdade para expandir suas práticas, desejando a mínima intervenção do Estado, que até ali era utilizado pelos monarcas para tolir liberdades e usurpar, por meio da cobrança de impostos, os burgueses bem-sucedidos.

Já no século $X X$, surgem os direitos fundamentais de segunda dimensão, também chamados de direitos sociais, permeados pelo ideal de igualdade e pela necessidade de intervenção estatal para garantir a efetivação de tais direitos.

Percebe-se mudança na forma de compreender a função do Estado em relação à sociedade, posto que a proposta absenteísta da dimensão anterior não conseguiu assegurar a dignidade humana, na medida em que não foi capaz de romper com as disparidades sociais, com a exploração econômica e com os efeitos nocivos da industrialização, dentre os quais destaca-se a exploração dos trabalhadores e formação de uma classe proletária e carente.

Dimoulis e Martins (2014) invocam a importância da Declaração dos direitos do povo trabalhador e explorado, redigida, em 1917, à época da Revolução Russa, para a constitucionalização dos direitos sociais. Os mesmos autores afirmam ter sido a Constituição Mexicana de 1917 o primeiro diploma normativo a dedicar-se, de forma pormenorizada, ao tema, apresentando longa lista de direitos sociais.

Com o fim da primeira grande guerra, a luta pela efetivação dos direitos fundamentais de segunda dimensão se tornou ainda mais intensa, sendo a Constituição alemã de 1919 Constituição de Weimar ${ }^{24}$ importante referencial histórico do período.

Em importante obra sobre o tema, Mendes (2011) coloca em evidência a impossibilidade financeira dos Estados de satisfazerem todas as necessidades sociais, defendendo a formulação

\footnotetext{
${ }^{24}$ A Constituição de Weimar apresenta extenso rol de direitos fundamentais, merecendo destaque os direitos a "educação e formação escolar" e a "ordem econômica". Por estar inserida em uma sociedade em situação de forte instabilidade política, sua vigência durou apenas 14 anos, terminado em janeiro de 1933, com a chegada de Adolf Hitler ao poder.
} 
de políticas públicas e, a partir delas, escolhas para fins de alocação dos recursos financeiros, técnicos e normativos.

De fato, os direitos sociais, por demandarem prestação econômica do Estado, são efetivados ou não, a depender das conjunturas econômicas e políticas lhes serem favoráveis ou desfavoráveis. Assim, estão submetidos ao princípio da reserva do possível, isto é, sujeitam-se às disponibilidades materiais do Estado.

Em decorrência de sua natureza de direito social, o direito fundamental à educação possui conteúdo prestacional, o que significa que a sua efetividade está a depender da atuação positiva do Poder Público, competindo a ele elaborar e implementar as políticas públicas direcionadas à concretização dos princípios e valores que estão a orientar a educação brasileira, o que implica na destinação de recursos financeiros e no acompanhamento de sua utilização.

Ainda sob o viés econômico/financeiro, cumpre registrar a necessidade de adotar critérios distributivos para cada recurso, vez que o Estado, para assegurar a efetivação de direitos sociais, como a saúde e a educação, demanda a utilização de recursos econômicos de forma variada, para atender a especificidade da questão e, por consequência, as necessidades de cada sujeito amparado.

Os direitos fundamentais de terceira dimensão são orientados pela solidariedade e concebidos numa perspectiva difusa, na medida em que interessam a todos os indivíduos, à sociedade e ao Estado, posto que são responsáveis por sua defesa e efetivação. Dentre os direitos fundamentais de terceira dimensão tem-se o direito ao meio ambiente equilibrado e ao desenvolvimento socioeconômico.

Fernandes (2017, p. 326-327) noticia a existência de direitos fundamentais de quarta e quinta dimensões, os primeiros relacionados à biotecnologia e o último relacionado à paz.

Os direitos fundamentais são assim dotados de historicidade, isto é, têm seu conteúdo e alcance estabelecidos em razão de um contexto histórico, não gozando da mesma valia em todo tempo e lugar. Impulsionados por novas causas sociais, tais direitos estão em constante processo evolutivo, ampliando-se gradativamente.

O texto constitucional de 1988 informa que as normas que estabelecem direitos e garantias fundamentais têm aplicação imediata, o que significa dizer que possuem força normativa densa, não estando sua implementação sujeita a ações do legislador infraconstitucional. Assim, os direitos fundamentais não precisam ser regulamentados por 
normas infraconstitucionais, na medida em que incorporados ao texto constitucional por meio das normas-princípio devem ser observados e instrumentalmente garantidos ${ }^{25}$.

A respeito de serem os direitos fundamentais normas-princípio, Sousa (2010, p.30) esclarece que tal característica: "aplica-se, inclusive aos direitos elencados no capítulo da ordem social, como o direito à educação, e constitui uma diretiva para o Poder Público no sentido de atribuir a esses direitos o máximo possível de efetividade".

Nesse ponto, há que se fazer menção ao princípio da proibição do retrocesso social que qualifica como inconstitucionais quaisquer ações do Estado no sentido de anular, revogar ou aniquilar os direitos sociais já efetivados pelas medidas legislativas. A aplicação deste princípio se dá de forma limitadora, impedindo ações políticas e legislativas que atentem contra direitos sociais, pois os mesmos são concebidos como conquistas da sociedade e, portanto, não podem, a qualquer argumento, ser dela retirado ou sofrer mitigações.

A Constituição Cidadã de 1988 foi minuciosa e precisa ao tratar dos direitos sociais, dedicando a eles um capítulo específico, idealizada quando já se percebia a falência do modelo liberal, cuidou de cobrar do Estado participação ativa, por meio das prestações positivas assegurando aos jurisdicionados o mínimo existencial.

Entende-se por mínimo existencial a menor quantidade possível de certo bem necessário ao viver com dignidade. Trata-se de medida fixada em atenção ao princípio da dignidade humana que, segundo Barcellos (2002, p.248) "é formado pelas condições materiais básicas para a existência, corresponde a uma fração nuclear da dignidade da pessoa humana à qual se deve reconhecer a eficácia jurídica positiva ou simétrica".

O direito à educação, por ser direito fundamental de segunda dimensão, um dos direitos sociais constitucionalmente previstos está submetido ao conceito de mínimo existencial, aplicando-se também a ele o princípio da proibição do retrocesso social.

Como mecanismo de proteção do direito fundamental à educação, o constituinte de 1988 inseriu este direito social dentre as cláusulas pétreas ${ }^{26}$, no chamado núcleo imutável, intangível

\footnotetext{
${ }^{25}$ Os instrumentos que garantem a observância dos direitos fundamentais são vários. A guisa de exemplos podem ser citados: "habbeas corpus", "habbeas data", mandado de segurança e ação civil pública.

26 Há polêmica acerca da inclusão dos direitos sociais, dentre eles o direito à educação, no rol de proteção das cláusulas pétreas. $\mathrm{O}$ argumento daqueles que se posicionam contrários a tal inclusão é no sentido de que 0 art.60 $\S 4^{\circ}$ da Constituição fala em "direitos e garantias individuais" e não em direitos fundamentais- gênero do qual são espécies os direitos sociais e os individuais. Assim, concluem, se os direitos sociais fossem cláusulas pétreas, o texto constitucional, teria feito menção expressa ou teria utilizado o gênero que os compreende. Em sentido contrário, os que defendem a inclusão, argumentam que as cláusulas pétreas servem para preservar os princípios fundamentais que orientaram o legislador constituinte e, sendo os direitos sociais inerentes à ideia de Estado Democrático de Direito, não faz sentido deixar de considerá-los cláusulas pétreas.
} 
da Constituição. Por consequência, o poder constituinte reformador não poderá suprimir ou restringir o núcleo destes direitos, estando protegido por este mecanismo.

\section{O DIREITO À EDUCAÇÃO E À LEGISLAÇÃO ESPECIALIZADA NO ENVELHECIMENTO}

No Brasil, além das garantias constitucionais, os direitos dos idosos encontram-se assegurados por leis especiais ou temáticas, dentre as quais merecem especial atenção e destaque: a Lei 8.842/1994 e a Lei 10.741/2003, que estabelecem a Política Nacional e o Estatuto do Idoso.

A Lei 8.842 entrou em vigor na data de sua publicação, em 04 de janeiro de 1994, tendo sido regulamentada pelo Decreto no 1.948/96. Com a finalidade de criar condições para promoção da autonomia, integração e participação efetiva do idoso na sociedade, a referida lei é um marco na luta pela efetivação dos direitos sociais dos idosos no Brasil.

A Política Nacional do Idoso foi estruturada a partir de cinco princípios ${ }^{27}$, merecendo destaque, para o enfrentamento da temática proposta, os que dispõem acerca do dever da família, da sociedade e do Estado de assegurar ao idoso sua condição de cidadão, defendendo a sua dignidade e bem-estar, o que implica em somar esforços para evitar e coibir qualquer tipo de ação ou omissão que se apresente discriminatória.

A mesma lei estabelece dentre as suas diretrizes a necessidade de viabilizar formas de participação, ocupação e convívio do idoso, mantendo-o integrado.

Para estar efetivamente integrado, ao idoso precisam ser oportunizadas todas as formas de interação social e de desenvolvimento pessoal oferecida aos integrantes de outras faixas etárias.

No que se refere ao direito à educação, necessário é percebê-lo como fonte de promoção da cidadania, por meio da gama de relacionamentos e da construção de saberes reflexivos que

${ }^{27}$ Lei 8.842/94. Art. $3^{\circ} \mathrm{A}$ política nacional do idoso reger-se-á pelos seguintes princípios:

I - a família, a sociedade e o estado têm o dever de assegurar ao idoso todos os direitos da cidadania, garantindo sua participação na comunidade, defendendo sua dignidade, bem-estar e o direito à vida;

II - o processo de envelhecimento diz respeito à sociedade em geral, devendo ser objeto de conhecimento e informação para todos;

III - o idoso não deve sofrer discriminação de qualquer natureza;

IV - o idoso deve ser o principal agente e o destinatário das transformações a serem efetivadas através desta política;

$\mathrm{V}$ - as diferenças econômicas, sociais, regionais e, particularmente, as contradições entre o meio rural e o urbano do Brasil deverão ser observadas pelos poderes públicos e pela sociedade em geral, na aplicação desta lei. 
suscita. Negar, restringir ou dificultar o acesso dos idosos a este direito é, portanto, discriminálos e condená-los ao ostracismo social.

Em $1^{\circ}$ de outubro de 2003, foi publicada a Lei 10.741, nacionalmente conhecida como Estatuto do Idoso. A referida lei, que passou a vigorar em todo território brasileiro em 1ำ de janeiro de 2004, tornou-se referência na temática do envelhecimento, estabelecendo o princípio da proteção integral e assegurando ao idoso o necessário para a "preservação de sua saúde física e mental e seu aperfeiçoamento moral, intelectual, espiritual e social, em condições de liberdade e dignidade"28.

Ao tratar dos direitos sociais, o referido Estatuto estabelece como dever de todos (família, sociedade e Poder Público) assegurar prioritariamente aos idosos brasileiros: "a efetivação do direito à vida, à saúde, à alimentação, à educação, à cultura, ao esporte, ao lazer, ao trabalho, à cidadania, à liberdade, à dignidade, ao respeito e à convivência familiar e comunitária"29.

Não obstante sua contribuição para o fortalecimento dos direitos fundamentais da pessoa idosa, certo é que, ainda que não tenha se omitido, o Estatuto mostrou-se tímido ao tratar do direito do idoso à educação, limitando-se assegurar-lhe "o direito a educação, cultura, esporte, lazer, diversões, espetáculos, produtos e serviços que respeitem sua peculiar condição de idade" 30 .

Ao tratar da criação de oportunidades de acesso do idoso à educação, a referida lei propõe “a adequação de currículos, metodologias e material didáticos"31.

Ainda que pareça louvável a preocupação em adaptar os instrumentos educacionais às necessidades dos idosos, o que por vezes se faz necessário para despertar interesse, valorizar experiências e facilitar o aprendizado; tal medida, da forma colocada, soa desrespeitosa e discriminatória. De fato, o Estatuto estabelece a adaptação dos instrumentos educacionais não como possibilidade, mas como condição de aprendizado, partindo do pressuposto de que todos os idosos, só pelo fato de o serem, têm limitações ao processo ensino/aprendizado.

Os atributos da generalidade e da abstratividade, comuns a todas as leis, não afasta a crítica; isto porque sendo genérica, a lei destina-se a todos, sendo abstrata está a serviço de um regramento geral e hipotético, não estando, a estes argumentos, legitimada a pressupor

\footnotetext{
${ }^{28}$ Art. $2^{\circ}$ da Lei $10.741 / 2003$.

${ }^{29}$ Art.3ํ da Lei 10.741/2003.

30 Art.20 da Lei 10.741/2003.

31 Art.21 da Lei 10.741/2003.
} 
deficiências, oferecendo a todos idosos tratamento que favoreça a discriminação, posto que alicerçado em preconceitos.

Ao dispor sobre cursos especiais para idosos, o Estatuto assegura que os mesmos "incluirão conteúdo relativo às técnicas de comunicação, computação e demais avanços tecnológicos, para sua integração à vida moderna"32. O Estatuto parece referir-se à educação não formal, utilizada para recreação e de forma terapêutica. Seu objetivo não é capacitar o idoso para inserção ou manutenção no mercado de trabalho, mas mantê-lo ativo e integrado à sociedade.

Também aqui, vale a advertência de que não há nenhum problema em se pensar, criar e oportunizar aos idosos brasileiros esse tipo de educação. Contudo, ao constatar que o Estatuto não se ocupa do direito e do acesso dos idosos à educação formal, o registro acerca dos cursos especiais parece indicar algo preocupante.

De fato, a educação do idoso foi tratada pelo Estatuto de forma, apenas, recreativa, retirando da temática a habitual seriedade com que é discutida tecnicamente. Dito de outra forma, mais uma vez a lei especializada demonstra desconhecer as várias velhices.

Pereira (2012) relata que ao entrevistar idosos alunos do EJA constatou que além de investimento pessoal e forma de preencher o tempo livre, o estudar é uma forma de autonomia, de aprendizado, de busca por melhores oportunidades de trabalho. Mostrando assim a necessidade de melhor entender este cidadão que envelhece para empreender políticas educacionais que atendam às suas expectativas e demandas.

Constata-se, pelos argumentos expostos, que o ordenamento jurídico brasileiro não oferece o melhor dos cenários ao enfrentamento da temática, sendo, por esta razão necessário refletir o direito fundamental à educação dos idosos à luz da cidadania para que não seja efetivada a negligência estatal e social à pessoa idosa quando se tratar do direito ao acesso e à efetivação da educação formal.

\section{EDUCAÇÃO E CIDADANIA}

O Direito à Educação, como anteriormente registrado, é assegurado pelo texto constitucional de 1988, sendo um direito fundamental de matiz social. A qualificação atribuída constitucionalmente à educação evidencia o valor contido neste direito, na medida em que o coloca em lugar de destaque na ordem constitucional brasileira. De fato, concebida como

32 Art.21 $\S 1^{\circ}$ da Lei $10.741 / 2003$. 
processo de transmissão de conhecimentos e valores, a educação mostra-se necessária ao desenvolvimento intelectual e social dos indivíduos, ferramenta indispensável à construção da cidadania.

O direito à educação se caracteriza pela incorporação de princípios e objetivos de caráter social que informam o Estado Democrático de Direito, sendo um importante instrumento de construção da cidadania e na promoção da dignidade da pessoa humana.

A educação precisa ser pensada como importante valor social, ferramenta que visa o desenvolvimento das potencialidades do indivíduo, bem como a sua autopercepção enquanto agente econômico, sujeito de direitos e de deveres na ordem social.

Além de um direito, a educação é um bem, um valor social necessário ao pleno desenvolvimento da pessoa, incluindo sua qualificação para o trabalho e para o exercício da cidadania. Assim, a inclusão social passa pelo acesso de todos a uma educação de qualidade, que potencialize o desenvolvimento intelectual, econômico e, consequentemente, social dos indivíduos.

Educar é formar cidadãos, isto é, pessoas com conhecimento técnico e consciência crítica. Não se restringe à transmissão de conhecimentos, sendo condição de libertação do próprio homem e, portanto, um direito humano fundamental.

O acesso a um sistema de ensino de qualidade ${ }^{33}$ possibilita o domínio de metodologias e linguagens necessárias para compreender o mundo e ter melhor qualidade de vida. Dito de outra forma, sem o acesso à educação o indivíduo está condenado à exclusão social. Por esta razão, é necessário ampliar os setores da população com acesso a sistema educacional eficiente e inclusivo.

O direito à educação cumpre assim relevante propósito social ao oferecer conscientização reflexiva e crítica, capaz de intervir a emancipação dos sujeitos, na medida em que se constitui uma das formas de se operacionalizar o princípio constitucional da dignidade da pessoa humana.

Nos termos do artigo $3^{\circ}$ da Constituição de 1988, constituem objetivos da República Federativa do Brasil a construção de uma sociedade livre, justa e solidária, a garantia ao desenvolvimento nacional, a erradicação da pobreza e da marginalização, com a consequente redução das desigualdades sociais e regionais, além da promoção do bem de todos, sem preconceitos de qualquer origem e quaisquer outras formas de discriminação.

\footnotetext{
33 É difícil mensurar a qualidade da educação. Vários são os sistemas de avaliação da educação no Brasil, todos, entretanto, profundamente questionados e desqualificados por especialistas. A democratização e a qualidade no ensino encontram barreiras como a deficiência e a baixa remuneração dos professores, a escassez de recursos financeiros, a ausência de políticas públicas que contemplem de forma eficiente e realista as demandas e possibilidades do sistema educacional brasileiro.
} 
A consecução de todos os objetivos expostos está intimamente ligada à educação, instrumento eficaz para superar desigualdades, desqualificar tratamentos discriminatórios, contribuindo para a formação de uma sociedade mais livre, justa e solidária, tendo em vista que atua na erradicação da pobreza e, por decorrência no desenvolvimento nacional.

Contudo, acessar o direito à educação não depende apenas do indivíduo a ser educado, trata-se de direito de conteúdo prestacional, isto é, estando sua efetivação a depender de conduta positiva do Estado no sentido de oferecê-lo.

Registre-se que o direito à educação deve ser acessível a todos, inclusive aos idosos. A idade avançada não pode ser utilizada como justificativa legítima para a subtração da aprendizagem, sendo necessário a revisão de conceitos, bem como a extinção de preconceitos acerca do direito à educação da pessoa idosa.

\section{ACESSO DOS IDOSOS À EDUCAÇÃO: UM DIREITO FUNDAMENTAL}

Como anteriormente registrado, este estudo se propôs a discutir o acesso dos idosos brasileiros à educação, direito fundamental e indispensável ao exercício da cidadania. Para tanto, buscou-se na síntese de indicadores de 2017 da Pesquisa Nacional por Amostra de Domicílios (PNAD) 2017 uma visão quantitativa do problema educacional brasileiro no que se refere ao aluno idoso.

A PNAD é uma pesquisa, com periodicidade variável, realizada pelo Instituto Brasileiro de Geografia e Estatística (IBGE) em uma amostra de domicílios brasileiros que investiga diversas características demográficas e socioeconômicas da população, tais como: sexo, idade, trabalho, educação, entre outros.

No Brasil, segundo dados da PNAD 2017, a taxa de analfabetismo é de 7,0\%, compreendendo um contingente de, aproximadamente, 11,5 milhões de analfabetos. Destes, 19,3\% estão acima dos 60 anos, ou seja, 2,9 milhões de cidadãos brasileiros. Estes números apresentam tendência de queda e variam de acordo com a região geográfica, estando no Nordeste o maior número de analfabetos, $14,5 \%$ e no Sul o menor percentual 3,5\% do total.

Merece registro o fato de que a taxa de analfabetismo mostra aumento à medida que a idade avança, sendo de $11,9 \%$ para os que estão na faixa etária dos 40 aos 59 anos, chegando a $7 \%$ entre os mais jovens que têm entre 15 e 19 anos.

Contudo, mais da metade da população alfabetizada apresenta baixo nível de instrução, assim, dentre os brasileiros escolarizados com 25 anos ou mais de idade $42,3 \%$ tinham até o 
ensino fundamental, $26,8 \%$ até o ensino médio completo e, apenas 15,7\% possuíam o superior completo.

Não há informações acerca da taxa de escolarização e nem de anos de escolaridade do idoso brasileiro, mas, pelos números apresentados percebe-se que muitos são analfabetos ou têm baixa instrução, indicando que o direito à educação não Ihes foi efetivamente assegurado e que as políticas públicas educacionais, até o momento, não lhes atingiram efetivamente.

Pesquisando as notas estatísticas do Censo da Educação Básica 2016, nenhuma informação foi encontrada acerca do idoso no ambiente educacional e esta omissão diz muito sobre o assunto. De fato, sabendo que os dados do censo são utilizados para a idealização e desenvolvimento de políticas públicas educacionais, a ausência dos alunos idosos nos dados do censo acarreta a ausência dos mesmos nas referidas políticas.

Assim, as políticas públicas educacionais brasileiras ainda não se atentaram para este novo sujeito e para suas demandas por uma educação capaz de mantê-lo ou (re) inseri-lo no mercado de trabalho bem como manter seu status quo no convívio social.

\section{CONCLUSÃO}

O idoso que busca a educação formal para se manter ou (re) inserir no mercado de trabalho está ausente nas discussões e nas agendas da política educacional brasileira. Tal ausência pode ser explicada sob vários argumentos: em primeiro lugar a senescência está fatalmente ligada à senilidade, nos acostumamos aos velhos decrépitos, derrotados pelo passar dos anos, com capacidade cognitiva severamente comprometida e, a esse perfil de sujeito social, não é dado o direito de acessar a educação formal.

Numa visão capitalista e utilitarista, considerando os idosos como seres improdutivos, resta a questão: para que aprender ou ensinar a alguém que não trará benefícios lucrativos à sociedade?

E o grande problema é que, muitas vezes, os idosos acabam aceitando esse rótulo de improdutivos e reverberando o preconceito e a segregação nele contidos, desistem de viver e de aprender, pois não querem a sensação de estarem "inadequados" ao voltarem para o ambiente escolar, historicamente direcionado às crianças e aos jovens. Daí a importância de se promover a conscientização não só dos agentes públicos e da sociedade, mas também (e sobretudo) dos idosos quanto aos benefícios decorrentes do acesso à educação e ao ambiente educacional. 
Ao tratar do direito à educação e ao envelhecimento, necessário perceber que se está diante de uma nova conjuntura social e que múltiplas são as velhices, demandando diferentes visões e caminhos educacionais.

Registre-se, por oportuno, a escassez de trabalhos acadêmicos conjugando as temáticas "envelhecimento" e "educação", razão pela qual sugere-se para futuras pesquisas a investigação acerca do acesso e permanência dos idosos no ensino superior e sobre políticas de educação permanente voltadas à pessoa idosa.

Neste sentido, Veloso e Rocha (2016) afirmam que a negligência das políticas públicas educacionais com as pessoas idosas é realidade global, sendo estes sujeitos sociais esquecidos quando o assunto da pauta é o direito à educação.

A educação é fundamental para a mudança desse panorama preconceituoso e discriminatório, que segrega os idosos. Assim o direito à educação não pode ser concebido como privilégio de gerações mais jovens, ao contrário, é direito fundamental de todos e deve ser um elemento da luta por uma sociedade mais coesa, harmônica, justa e desenvolvida.

\section{REFERÊNCIAS}

BARCELLOS, Ana Paula. A eficácia jurídica dos princípios constitucionais: o princípio da dignidade da pessoa humana. Rio de Janeiro: Renovar, 2002. Google

BELTRÃO, Kaizô Iwakami; CAMARANO, Ana Amélia; KANSO, Solange. Dinâmica populacional brasileira na virada do século XX. Rio de Janeiro: IPEA, ago. 2004. Google

BEZERRA, Fernanda Carvalho; ALMEIDA, Maria Irismar; THERRIEN, Silvia Maria Nóbrega. Estudos sobre envelhecimento no Brasil: revisão bibliográfica. Rev. Bras. Geriatr.

Gerontolog., Rio de Janeiro, 2012. Google

BOBBIO, Norberto. O Tempo da Memória. De Senectute e Outros Escritos Autobiográficos. Rio de Janeiro: Campus. 1997.

BRASIL. Lei 3.270, de 28 de setembro de 1885. Lei dos Sexagenários. Disponível em: http://www.planalto.gov.br. Acesso em: 01 maio 2018.

BRASIL. Constituição Federal da República Federativa do Brasil, de 05 de outubro de 1988. Disponível em: http://www.planalto.gov.br. Acesso em: 04 maio 2018.

BRASIL. Lei 8.842, de 04 de janeiro de 1994. Institui a Política Nacional do Idoso. Disponível em: http://www.planalto.gov.br. Acesso em: 01 maio 2018.

BRASIL. Decreto 1.948, de 03 de julho de 1996. Regulamenta Lei 8.842/94. Disponível em: http://www.planalto.gov.br. Acesso em: 01 maio 2018. 
BRASIL. Lei 10.741 de 01 de outubro de 2003. Estatuto do Idoso. Disponível em: http://www.planalto.gov.br. Acesso em: 01 maio 2018.

BRITO, Fausto. Transição demográfica e as desigualdades sociais no Brasil. Revista Brasileira de Estatística Populacional, São Paulo, v. 25, n. 1, p. 5-26, jan./jun. 2008. Disponível em: http://www.scielo.br/pdf/rbepop/v25n1/v25n1a02.pdf. Acesso em: 17 maio 2018. Google

CABRAL, Manuel Villaverde; FERREIRA, Pedro Moura. O envelhecimento activo em Portugual: trabalho, reforma, lazer e redes sociais. Lisboa: Fundação Francisco Manuel dos Santos, 2013. Google

CAMARANO, Ana Amélia (Org.). Cuidados de longa duração para a população idosa: um novo risco social a ser assumido? Rio de Janeiro: Ipea, 2010. Google

DIMOULIS, Dimitri; MARTINS, Leonardo. Teoria geral dos direitos fundamentais. 5. ed. São Paulo: Atlas, 2014.

DINIZ, Fernanda Paula. Direitos dos idosos na perspectiva civil-constitucional. Belo Horizonte: Arraes Editores, 2011.

DOURADO, Luiz Fernandes. Reforma do Estado e as Políticas para a educação superior no Brasil nos anos 90. Educ. Soc., Campinas, v. 23, n. 80, p. 234-252. Setembro/2002. Disponível em: http://www.scielo.br/pdf/es/v23n80/12931.pdf. Acesso em 12 maio 2017. Google

FERNANDES, Bernardo Gonçalves. Curso de Direito Constitucional. 9. ed. Salvador: JusPODIVM, 2017.

HADDAD, Eneida Gonçalves Macedo. $\mathbf{O}$ direito à velhice: os aposentados e a previdência social. São Paulo: Cortez, 1993.

IBGE - Instituto Brasileiro de Geografia e estatística. Censo 2010. Disponível em: https://censo2010.ibge.gov.br/resultados.html. Acesso em: 11 de maio de 2018.

KALACHE, Alexandre. Envelhecimento populacional no Brasil: uma realidade nova. Cadernos de Saúde Pública, São Paulo: v. 3, p. 217-220, 1987.

KALACHE, Alexandre. O Século do Envelhecimento e Sociedade que Queremos Construir. Revista Direitos Humanos, v. 3, p. 30-35, 2009.

LIBERATI, Wilson Donizeti (Org.). Direito à Educação: uma questão de justiça. São Paulo: Malheiros, 2004.

MARTINEZ, Wladimir Novaes. Comentários ao Estatuto do Idoso. 3. ed. São Paulo: LTr, 2012.

MARTINS, Flávio Alves Nunes. Curso de Direito Constitucional. São Paulo: Revista dos Tribunais, 2017.

MASCARO, Sônia Amorim. O que é velhice. São Paulo: Brasiliense, 1997. 
MENDES, Gilmar Ferreira; COELHO, Inocêncio Martinez; BRANCO, Paulo Gustavo Gonet. Curso de Direito Constitucional. São Paulo: Saraiva, 2007.

MENDES, Gilmar Ferreira. Direitos fundamentais e controle de constitucionalidade Estudos de Direito Constitucional. 4. ed. São Paulo: Saraiva, 2011.

NUNES, Luiz Antônio Rizzatto. O princípio constitucional da dignidade da pessoa humana: doutrina e jurisprudência. São Paulo: Saraiva, 2002.

OMS. Envelhecimento ativo: uma política de saúde / World Health Organization; tradução Suzana Gontijo. - Brasília: Organização Pan-Americana da Saúde, 2005. 60 p.: il.

RAMOS, Paulo Roberto Barbosa. Fundamentos Constitucionais do Direito à velhice. Florianópolis: Obra Jurídica, 2014.

SARLET, Ingo Wolfgang. A eficácia dos direitos fundamentais. 3. ed. Porto Alegre: Livraria do Advogado Editora, 2003.

SARMENTO, Daniel. Dignidade da Pessoa Humana. 2. ed. Belo Horizonte: Editora Forense, 2016.

SEALE, Atlanta Sloane; KOPS, Bill. Relação entre aprendizagem dos idosos e envelhecimento bem sucedido. Fragmentos de cultura. Goiânia,v. 22, n. 1, p. 25/36 jan.-mar., 2012. Google

SILVA, Joana Mafalda Amaral Vieira da. A qualidade de vida do idoso e o seu bem-estar social. 130 f. Dissertação (Mestrado em Educação Social), Escola Superior de Educação e Comunicação, Universidade do Algarve, 2011. Google

SOUSA, Eliane Ferreira. Direito à educação: requisito para o desenvolvimento do país. São Paulo: Saraiva, 2010.

VELOSO, Esmeraldina Maria Costa, ROCHA, Maria Custódia Jorge. Políticas públicas, pessoas idosas, educação e envelhecimento: o caso de Portugal num contexto global. Revista do Instituto de Políticas Públicas de Marília, Marília, v. 2, n. 1, p. 3-37 jan.- jun., 2016. Disponível em:

http://www2.marilia.unesp.br/revistas/index.php/RIPPMAR/article/download/6275/4152. Acesso em: 01 maio 2018.

VERAS, Renato Peixoto. País jovem com cabelos brancos: a saúde do idoso no Brasil. Rio de Janeiro: Relume Dumará, 1994. Google

VIEIRA, Tereza Rodrigues; NASCENTES, Claudiene. O idoso, a publicidade e o Direito do consumidor. Jus Navegandi, Teresina, ano 9, n.179, 1 jan. 2004. Disponível em:

http://www1.jus.com.br/doutrina/texto.asp?id=4621. Acesso em: 01 maio 2018.

VOGT, Maria Saleti Lock; ALVES, Elioenai Dornelles. Revisão teórica sobre a educação de adultos para uma aproximação com a andragogia. Educação, Santa Maria, v. 30, n. 2, p.195214, 2005. Disponível em: http://ufsm/ce/revista. Acesso em 12 maio 2017. Google 